\title{
Defining risks and predicting adverse events after lower extremity bypass for critical limb ischemia
}

\author{
This article was published in the following Dove Press journal: \\ Vascular Health and Risk Management \\ 23 June 2014 \\ Number of times this article has been viewed
}

\author{
Jeffrey J Siracuse \\ Zhen S Huang \\ Heather L Gill \\ Inkyong Parrack \\ Darren B Schneider \\ Peter H Connolly \\ Andrew J Meltzer \\ Division of Vascular and Endovascular \\ Surgery, New York-Presbyterian \\ Hospital, Weill Cornell Medical \\ College, New York, NY, USA
}

\begin{abstract}
Successful treatment of patients with critical limb ischemia (CLI), hinges on the adequacy of revascularization. However, CLI is associated with a severe burden of systemic atherosclerosis, and patients often suffer from multiple cardiovascular comorbidities. Therefore, CLI patients in general represent a cohort at increased risk for procedural complications and adverse events. Although endovascular therapy represents a minimally invasive alternative to open surgical bypass, the durability of surgical reconstruction is superior, and it remains the "gold standard" approach to revascularization in CLI. Therefore, selection of the optimal treatment modality for individual patients requires careful consideration of the procedural risks and likelihood of adverse events associated with surgery. Individualized decision-making with regard to revascularization strategy requires a comprehensive understanding of the likelihood of adverse outcomes after major surgery. Here we review the risks of surgical bypass in patients with CLI, with particular emphasis on the identification of preoperative variables that predict poor outcome.
\end{abstract}

Keywords: critical limb ischemia, bypass, adverse events

\section{Introduction}

Peripheral vascular disease affects approximately up to 10 million Americans with approximately $1 \%$ having critical limb ischemia (CLI). ${ }^{1}$ Despite the increased utilization of minimally invasive endovascular interventions for CLI, surgical bypass remains the gold standard against which all minimally invasive treatments are measured. Less invasive therapies may offer a more favorable perioperative safety profile, therefore making them preferable in high risk patients, whereas the durability of endovascular interventions is superior. ${ }^{2-5}$ Therefore, optimal decision-making for an individual patient hinges on careful risk stratification and consideration of patients' suitability for surgical reconstruction. Because patients with CLI commonly suffer from associated comorbidities, they represent a "high risk" cohort, in which adverse events are not uncommon. Multiple studies have suggested that perioperative mortality exceeds $2 \%$, with complication rates exceeding $20 \%$ in some groups. ${ }^{6,7}$

Furthermore, these patients are at relatively high risk for hospital readmission and increased length of stay (LOS) postoperatively. The objectives of this review are to summarize existing data regarding the risks associated with surgical bypass in this unique patient population. To accomplish this, we assess historic and contemporary outcomes data to estimate the incidence of adverse events after surgical bypass, and describe recent efforts to develop targeted risk assessment tools to improve perioperative risk stratification.
Correspondence: Jeffrey J Siracuse

Weill Cornell Medical College,

525 68th Street, New York,

NY I002I,USA

Email jes9061@nyp.org
Vascular Health and Risk Management 2014:10 367-374 


\section{Perioperative risk assessment}

Generalized risk prediction models have been developed to stratify surgical patients with respect to perioperative risk. The most widely accepted model is the American Society for Anesthesiology (ASA) Classification. ${ }^{8}$ This generalized scoring system stratifies patients into categories based on their comorbidities and the subsequent risk to their everyday life to establish how fit they are to undergo an operation. There are no specific conditions mentioned and there is room for a lot of variability. The surgical risk score and American College of Surgeons Risk Calculator represent increasingly more detailed efforts to estimate the risks of surgery for a wide range of surgical procedures across many different specialties. ${ }^{910}$ More specific risk assessment tools have been created to predict postoperative mortality in specific patient populations, including those undergoing pancreatic surgery, bariatric surgery, and colorectal procedures. ${ }^{10-12}$

Due to the high prevalence of cardiovascular risk factors, estimation of preoperative cardiac risk has traditionally been the focus of more specific efforts, and preoperative cardiac evaluation. The most widely accepted tool used to predict cardiac risk is the Revised Cardiac Risk Index, with patients often referred for preoperative cardiac evaluation. ${ }^{13}$ Preoperative cardiac evaluation is often obtained before major vascular surgery. However, the utility of such assessment has recently been questioned, with respect to perioperative and long-term outcomes, by Monahan et al. ${ }^{14}$ The authors identified all patients that met the American College of Cardiology and the American Heart Associations' criteria for preoperative cardiac evaluation. These patients were divided into two groups - those who underwent preoperative cardiac evaluation and those who did not. In the group that received a workup, $13 \%$ underwent coronary revascularization; this was divided into $60 \%$ percutaneous and $40 \%$ coronary artery bypass. Patient survival at 12 months for the group without a workup compared to those who had a cardiac workup, and to those who were revascularized was $85.3 \%, 78.5 \%$, and $80.0 \%$, respectively and $73.6 \%, 62.9 \%$, and $80.0 \%$, respectively at 36 months - showing no significant difference. Median length of hospitalization was also not significantly different. ${ }^{14}$ In an effort to more specifically assess cardiac risk, members of the Vascular Study Group of New England (VSGNE) utilized multi-institutional surgical outcomes data to develop a targeted risk assessment tool for cardiac risk in patients undergoing lower extremity revascularization. ${ }^{15}$ Other efforts to predict outcome in this patient population include the PREVENT (PRoject of Ex vivo vein GRaft Engineering via Transfection) III Score, which predicts the likelihood of mortality or amputation at 1 year. $^{7}$

The limitations of these existing models for preoperative risk stratification are apparent. Generalized models (eg, ASA classification, surgical risk score) may have limited applicability with respect to the high risk population with CLI. Existing efforts to predict "risk" specifically in this patient population (PREVENT III Score, VSGNE), however, have tended to focus on prediction of mortality and/or adverse cardiac events, without specifically addressing the occurrence of major morbidity that is not related to cardiac disease, but certainly may negatively impact quality of life in surgical patients.

Our group has previously published a more comprehensive, targeted risk assessment tool to predict 30-day major morbidity and mortality after bypass surgery for CLI; The Comprehensive Risk Assessment for Bypass. ${ }^{6}$ A review of the American College of Surgeons-National Surgical Quality Improvement Program (ACS-NSQIP) found that the 30-day mortality rate after lower extremity bypass for CLI was $2.9 \%$, with a major morbidity at a rate of $19.1 \%{ }^{6}$ The composite major morbidity and mortality end point was seen in $10.1 \%$ of patients. Significant predictors by multivariate analysis included age $>75$ years, prior amputation or revascularization, tissue loss, dialysis dependence, severe cardiac disease, emergency operation, and functional dependence. When weighed based on the odds ratio for morbidity and mortality, total functional dependence and emergent case were assigned 6 points each, recent angina/ myocardial infarction and dialysis dependence were assigned 4 points, and advanced age, prior lower extremity intervention, ulceration, and partial functional dependence were given 3 points. High risk patients ( $>12$ points) had a $25 \%$ rate of major morbidity and mortality within 30 days, medium risk (7-12) had a $13 \%$ risk, and low risk (0-6) had a $6 \%$ chance for major morbidity and mortality within 30 days. ${ }^{6}$

Not surprisingly, there is considerable overlap in these models of risk prediction (Table 1). Certain patientlevel factors have repeatedly been shown to portend poor outcome in patients with CLI undergoing surgical bypass (Table 2). Several distinct patient groups warrant more indepth discussion.

\section{Advanced age}

Elderly patients are generally at higher risk for perioperative events. ${ }^{16,17}$ However, a retrospective review of 262 lower extremity bypasses, almost all for CLI, in octogenarians showed promising results. ${ }^{18}$ The 5 -year primary, assisted 
Table I Perioperative risk assessment strategies

\begin{tabular}{|c|c|c|}
\hline Model & Variables & Comment \\
\hline American Society of Anesthesiology (ASA) & Degree of systemic disease & Assess overall fitness for surgery \\
\hline $\begin{array}{l}\text { American College of Surgeons Risk } \\
\text { Calculator }\end{array}$ & $\begin{array}{l}\text { Age, sex, BMI, ASA class, functional status, } \\
\text { case urgency, wound class, steroid use, } \\
\text { ascites, sepsis, ventilated, disseminated cancer, } \\
\text { diabetes, hypertension, previous cardiac event, } \\
\text { CHF, dyspnea, smoker, COPD, dialysis, ARF }\end{array}$ & $\begin{array}{l}\text { Assess risks for perioperative } \\
\text { mortality as well as specific } \\
\text { complications }\end{array}$ \\
\hline Surgical Risk Score & Case urgency, ASA class, case complexity & $\begin{array}{l}\text { Predicts mortality and major } \\
\text { morbidity }\end{array}$ \\
\hline Revised Cardiac Risk Index & $\begin{array}{l}\text { CAD, CHF, history of CVA/TIA, diabetes, } \\
\text { CRI, intra-abdominal/intra-thoracic surgery }\end{array}$ & $\begin{array}{l}\text { Risk of cardiac death, nonfatal } \\
\text { myocardial infarction, and } \\
\text { nonfatal cardiac arrest }\end{array}$ \\
\hline PREVENT III & Dialysis, CAD, tissue loss, anemia, age & $\begin{array}{l}\text { Predictor of death or major } \\
\text { amputation in I year }\end{array}$ \\
\hline VSGNE & $\begin{array}{l}\text { Age, smoking, beta-blocker use, COPD, CRI, } \\
\text { CHF, CAD, diabetes }\end{array}$ & $\begin{array}{l}\text { Risk of perioperative cardiac } \\
\text { events }\end{array}$ \\
\hline $\begin{array}{l}\text { Comprehensive Risk Assessment for } \\
\text { Bypass (CRAB) }\end{array}$ & $\begin{array}{l}\text { Age, dialysis dependence, tissue loss, } \\
\text { functional status, severe cardiac disease, } \\
\text { emergency operation, prior amputation/ } \\
\text { revascularization }\end{array}$ & $\begin{array}{l}\text { Predictor of } 30 \text {-day major } \\
\text { morbidity and mortality }\end{array}$ \\
\hline
\end{tabular}

Abbreviations: ARF, acute renal failure; BMI, body mass index; CAD, coronary artery disease; CHF, congestive heart failure; COPD, chronic obstructive pulmonary disease; CRI, chronic renal insufficiency; CVA, cerebrovascular accident; PREVENT, PRoject of Ex vivo vein GRaft Engineering via Transfection; VSGNE, Vascular Study Group of New England; TIA, transient ischemic attack.

primary, and secondary graft patency rates in octogenarians were $72 \%, 80 \%$, and $87 \%$, respectively. The 5 -year limb salvage rate was $92 \%$ and patient survival was $44 \%$. On average, both residential and ambulatory statuses significantly improved postoperatively. Although advanced age is a risk factor for adverse events, lower extremity bypass can safely be performed and preserve ambulatory status and independence. ${ }^{18}$ Furthermore, when comparing open versus endovascular revascularization in the elderly, both groups had similar decreases in functional status post-procedure; however, the open bypass group had an advantage at 6 months compared with the endovascular group in regards to functional status. ${ }^{19}$

On the other end of the age spectrum, patients younger than 40 years old are also at increased risk for poor outcomes. The majority of these patients have juvenile diabetes. Perioperative morbidity and mortality is low, however graft failure is high with 30 -day graft failure being $11 \%$, and 1 -year

Table 2 Shared high risk groups

Coronary artery disease
Dialysis dependence
Advanced age
Impaired functional status
Tissue loss
Emergency operation
Congestive heart failure
Smoking
Chronic obstructive pulmonary disease

primary patency of $71.0 \%$, secondary patency of $82.5 \%$, and limb salvage of $87.1 \%$. At 5 years, these rates have been reported as $51.9 \%, 63.4 \%$, and $77.2 \%$, respectively. Overall survival at 1 year was $88.2 \%$ and at 5 years was $73.3 \%$ with patients with renal dysfunction, in particular, having poorer survival (Table 3). ${ }^{20,21}$

\section{Sex}

In our progressively aging population, women 65 years of age and older outnumber their male counterparts by $>30 \%$, and by more than twice for women aged 85 years and over. Prior studies have demonstrated sex-related differences in vascular diseases such as abdominal aortic aneurysm (AAA) and carotid disease. Hypotheses to explain these differences have ranged widely from biochemical, anatomical, and social factors. A recent study analyzing sex disparities in patients with intermittent claudication and CLI using the National Inpatient Sample (NIS) demonstrated salient differences in presentation, revascularization modality, and amputation and inpatient mortality rates based on patient sex. At presentation, women were older (by an average of 3.5 years) and more likely to have CLI than intermittent claudication compared to men. Of those patients undergoing a revascularization procedure, CLI was a more common indication for women and they were more likely to undergo endovascular interventions for both intermittent claudication and CLI. The amputation and inpatient mortality rates have been declining over the years for both sexes. Interestingly, in-hospital mortality was 
Table 3 Subgroup patency

\begin{tabular}{lllll}
\hline Demographic & $\begin{array}{l}\text { Patency } \\
\text { rate }\end{array}$ & $\begin{array}{l}\text { CLI } \\
\text { Octogenarians }\end{array}$ & $\begin{array}{l}\text { Tibial } \\
\text { target }\end{array}$ & $\begin{array}{l}\text { Duration } \\
\text { of follow-up }\end{array}$ \\
Younger than 40 & $72 \%$ & $96 \%$ & $76 \%$ & 5 years ${ }^{18}$ \\
African-American & $52 \%$ & $87 \%$ & $46 \%$ & 5 years \\
Renal transplant & $44 \%$ & $95 \%$ & $78 \%$ & 5 years $^{26}$ \\
Arm vein conduit & $52 \%$ & $99 \%$ & $84 \%$ & 3 years \\
Prosthetic conduit & $60 \%$ & $96 \%$ & $100 \%$ & 5 years $^{28}$ \\
Severely calcified target & $60 \%$ & $90 \%$ & $100 \%$ & 2 years \\
\hline
\end{tabular}

Abbreviation: CLI, critical limb ischemia.

found to be persistently higher in women than men regardless of disease severity or intervention performed. Given these data, sex-based differences are apparent in lower extremity peripheral artery disease (PAD) presentation, management, and outcomes. Further studies will be required to elucidate the underlying causes for these incongruences. ${ }^{22}$

\section{Race}

Race has been shown to affect outcomes in many medical conditions, including in postoperative vascular surgery patients. ${ }^{23}$ A retrospective review showed that African-American patients compared to Caucasians undergoing bypass for CLI, although younger, had higher rates of diabetes, hypertension, cerebrovascular disease, congestive heart failure, dialysis dependence, and were more likely to present with gangrene. ${ }^{24}$ Vein conduit and target vessels were similar between the two groups. Overall morbidity and mortality were similar between the two groups, however patency and limb salvage outcomes were worse in the African-American group. Thirtyday graft failure was $12 \%$ in African-Americans versus $5 \%$ in Caucasians; $P=0.003$. The overall 5 -year primary graft patency was also significantly worse in African-American patients ( $52 \%$ versus $67 \% ; P=0.009$ ) as was the 5 -year limb salvage rate ( $81 \%$ versus $90 \%)$. In multivariate analysis, African-American race was an independent predictor of primary graft failure along with young age, female sex, secondary reconstructions, tibial bypasses, and CLI (Table 3). ${ }^{24}$

\section{Preoperative functional status}

Poor preoperative functional status has consistently been shown to be a negative predictor of outcome after lower extremity procedures. It is an independent risk factor for prolonged LOS as well as morbidity and mortality after infrainguinal lower extremity bypass. This morbidity and mortality risk in the perioperative phase is particularly pronounced in patients with dependent functional status combined with an emergency operation and/or dialysis dependence. ${ }^{16}$
Furthermore, in postoperative patients, improvements in quality of life measures were significantly better in those who had better baseline functionality than those who did not. These measures included greater improvement in activities of daily living and mental well-being. Physical symptoms such as extremity cramping and pain both when walking and at rest, and wounds, were also improved. Those who had a better subjective preoperative functionality seemed to have the most improvement. ${ }^{25}$

\section{End stage renal disease and renal transplant patients}

End stage renal disease is a comorbidity universally associated with poor outcomes. Given the prevalence of chronic kidney dysfunction and the associated poor outcomes in bypass patients with CLI, this group warrants particular attention. ${ }^{6,715}$ Even though renal failure patients are at high risk for mortality after bypass for CLI, patients with a kidney transplant seemed to fair better than those who remain on dialysis. ${ }^{27} \mathrm{~A}$ retrospective single-center review showed that the overall major complication rate was $11.8 \%$ and the 30 -day mortality rate was $1.3 \%$ for lower extremity bypass for CLI in renal transplant patients. At 1 year, survival was $93.3 \%$ and at 5 years it was $66.6 \%$. Limb salvage was $87 \%$ at 1 year and $78 \%$ at 5 years. Primary graft patency was $78 \%$ at 1 year and $44 \%$ at 5 years. Those who had a wellfunctioning allograft, as classified by a serum creatinine of less than $2.0 \mathrm{mg} / \mathrm{dL}$, had improved 5-year survival (73.4\% versus $37.5 \% ; P=0.01$ ), but no difference in limb salvage and patency (Table 3 ). ${ }^{26}$

\section{Procedural factors}

In addition to the aforementioned patient-level factors, such as demographics and comorbidities, that have been associated with poor outcome, specific procedural details may define groups at higher risk for adverse events.

\section{Conduit choice}

The ideal conduit is the ipsilateral greater saphenous vein; however, this is not always available. One alternative autologous vein that shows good results is an arm vein. The majority of these cases were distal/tibial revascularizations that used a single vein. The source was the cephalic vein alone in $50.4 \%$ of cases, the cephalic and basilic vein in $35.6 \%$, and the basilic vein alone in $14 \%$. In many of these cases (39\%), the contralateral saphenous vein was suitable. Vein configuration and splicing did not affect patency rates. Early patency was excellent at $94.8 \%$ at 30 days. At 1 year 
the primary patency rate at 1 year was $70.6 \%$, the secondary patency rate was $76.9 \%$, and the limb salvage rate was $88.2 \%$. The 3 -year primary patency rate was $51.9 \%$. In $22.7 \%$ of patients, the available contralateral saphenous vein was used for distal revascularization. It was recommended that an arm vein be used as the next option when the ipsilateral greater saphenous vein is not available and even if the contralateral greater saphenous vein is available - preserving it for future bypass on the other leg or for coronary bypass. ${ }^{27}$

When no autologous conduit is available, bypasses to tibial vessels using prosthetic material (polytetrafluoroethylene) can be successfully used. In cases where prosthetic graft is used to construct a bypass primary patency rates have been reported as $87 \%, 87 \%$, and $60 \%$ at 30 days, one year, and 5 years respectively. ${ }^{28}$ Limb salvage rates at 30 days, 1 year, and 5 years were $91 \%, 68 \%$, and $63 \%$, respectively. Cumulative survival rates at 3 and 5 years, however, were $53 \%$, and $42 \%$, respectively. The 29 grafts $(64 \%)$ that were postoperatively anticoagulated with warfarin showed a trend toward improved primary patency ( $47 \%$ versus $19 \%, P=0.07$ ), secondary patency ( $49 \%$ versus $20 \%, P=0.03$ ), and limb salvage $(67 \%$ versus $58 \%, P=0.06)$, at 3 years. There were no significant differences between diabetics and non-diabetics except in a trend toward decreased patient survival at 3 and 5 years in the diabetic population. ${ }^{28}$

As an alternative, either in cases where there is poor conduit or as primary treatment, endovascular techniques can be used. Advances such as drug eluding and covered stents have been used with good short-term results for femoral-popliteal disease. Drug eluding stents at 2 years showed a $75 \%$ primary patency. ${ }^{30}$ Heparin-bonded covered stents had a primary patency of $71 \%$ at 1 year but fared worse at 3 years $(24 \%) .{ }^{31}$ Drug eluding balloons also have promising short-term results compared to standard balloon angioplasty. ${ }^{32}$ However, these studies contain a large percentage of claudicants. Long-term outcomes and outcomes in CLI patients remain unclear as the majority of these patients studied were claudicants.

\section{Distal anastomotic target}

Comparison between those arteries that were assessed as severely calcified and unclampable to those that were not, showed no significant short- and long-term differences in outcomes. Primary patency, secondary patency, and foot salvage rates at 24 months were $60 \%, 65 \%$, and $77 \%$, respectively for the severe calcification group, which did not significantly differ from the no calcification group rates of $74 \%, 82 \%$, and $93 \%$, respectively. ${ }^{33}$ Perioperative mortality $(0.99 \%$ severe calcification verses $0.95 \%$ no calcification) and 24-month survival rates (84\% severe calcification versus $83 \%$ no calcification) were also similar between groups. Severely calcified, unclampable outflow arteries can be bypassed with results comparable to those obtained with clampable, uncalcified vessels. This population should not be ruled out for bypass for limb salvage indications (Table 3). ${ }^{33}$

Another difficulty seen with target vessels is when there is a local infection near the area. A retrospective review discussed treatment of bad diabetic foot infections where the target vessel was the dorsalis pedis artery. ${ }^{34}$ Achieving adequate control of the infection and sepsis prior to the bypass was important to success. Bypasses were delayed by an average of almost 11 days due to the need to control the infection. Graft patency in such cases was $92 \%$ at 36 months and limb salvage was $98 \%$ at 36 months. ${ }^{34}$

In cases where the main pedal vessels are not adequate targets, plantar and tarsal vessels are options. Inframalleolar bypass can be used even when previous bypass more proximally has failed. These bypasses have acceptable patency rates; however, compared to main tibial vessel bypass, these have higher rates of graft failure and limb loss. Saphenous vein conduit had the best patency. ${ }^{35}$

\section{Predicting postoperative infectious complications}

Surgical site infections (SSI) are one of the most common complications after lower extremity bypass. SSI were seen in up to $11 \%$ of cases 30 days postoperatively regardless of bypass origin. ${ }^{37}$ Graft failure was also significantly associated with postoperative SSI. Independent predictors of SSI were obesity, diabetes, poor preoperative functional status, a history of smoking, and female sex. ${ }^{36,37}$

One of the most morbid complications postoperatively is a prosthetic graft infection. Graft infection, as defined by exposed graft or presence of purulent fluid around a graft, has been reported in up to $3.8 \%$ of bypasses using prosthetic graft. ${ }^{38}$ Independent predictors of graft infection have been identified as a redo bypass, active infection at the time of bypass, female sex, and diabetes mellitus. Graft infection was predictive of major lower extremity amputation along with preoperative tissue loss. However, graft infection did not predict long-term mortality whereas chronic renal insufficiency and preoperative tissue loss both did. Infected grafts were removed $79 \%$ of the time. More have been able to be salvaged in recent years with treatment with vacuum assisted device placement and in some cases 
rotational muscle flaps. Staphylococcus epidermidis (37\%) and methicillin-sensitive Staphylococcus aureus (26\%) were the most common pathogens isolated. It was recommended in these high risk patients that autologous vein for lower extremity bypass and endovascular interventions should be considered when feasible. ${ }^{38}$

\section{LOS and readmissions}

Admissions of PAD with CLI are associated with prolonged and costly hospitalizations. This is particularly true for patients in the postoperative phase after infrainguinal bypass for CLI. Prolonged LOS and readmissions are both costly to hospitals and are seen as a measure of poor quality of care. ${ }^{39-41}$ This is not only due to these patients' significant comorbidities, but also the continued wound care, additional procedures during the hospitalization, postoperative complications, and difficulty placing these patients due to functional impairment.

The average LOS after lower extremity bypass for CLI is 7.5 days with a median of 6 days. There are several variables that can be identified in the preoperative phase that predict prolonged LOS. The highest predictive variables include impaired functional status, prolonged preoperative hospitalization greater than 5 days, and emergency surgery. Impaired functional status represents an overall debilitated patient as well as some who can be difficult to place postoperatively. Prolonged preoperative hospitalization not only possibly represents more severe disease and sicker patients, but it also puts the patients at risk for nosocomial infections. Other factors associated with increased LOS include demographic factors such as advanced age and nonCaucasian race. Medical comorbidities that significantly increased LOS included obesity, dialysis dependence, cardiac and pulmonary comorbidities, and bleeding disorders/chronic anticoagulation. More severe PAD disease, as noted by distal target sites, open wounds or gangrene, and prior arterial surgery also increased LOS. ${ }^{17}$

Identification of preoperative risk factors for prolonged LOS allows for the development of pathways that potentially can identify high risk patients in the preoperative phase. This would allow a multidisciplinary approach with the vascular surgeon, medical subspecialists, physical therapists, and social workers who can preemptively intervene to try and decrease LOS. However, data showing success of such efforts to decrease postoperative LOS without sacrificing health care quality are still pending. ${ }^{17}$

Similar to protracted LOS, readmissions after lower extremity bypass for CLI are costly. Readmissions continue to be viewed as a quality of care indicator and are targets for decreased reimbursement to hospitals. Efforts to decrease LOS should be balanced with maintaining a low readmission rate. CLI patients are particularly at risk for early postoperative readmission due to wound complications and significant comorbidities.

In a retrospective analysis of a large multi-institutional series, the average readmission rate for CLI patients $\leq 30$ days of discharge after lower extremity bypass was shown to be $24.4 \%{ }^{42}$ The most frequent reason for readmission was a wound infection in the bypassed extremity $(39.8 \%)$, followed from a need for additional procedures on the affected leg, and nonvascular reasons (19\%). The highest risk factor for readmission that could be identified in the preoperative phase was dialysis dependence followed by loss of graft patency during initial admission, tissue loss, current smoking, and female sex. Thirty-day readmission rates were as high as 38\% for the highest risk patients. Thirty-day readmission was not associated with loss of long-term graft patency but was associated with long-term limb loss. ${ }^{42}$

ACS-NSQIP analysis of readmissions showed an 18\% readmission rate within 30 days. This showed similar risk factors for readmission including dependent functional status, dialysis, dyspnea, obesity, CLI, and a return to the operating room during the initial admission. The most common readmission indications included wound infection $(37 \%)$ and graft failure $(10 \%){ }^{43}$

\section{Adjuncts}

\section{Common femoral endarterectomy}

Common femoral endarterectomy with or without profundaplasty is often performed with a distal revascularization for severe concurrent obstructive lesions in the common femoral artery. This alone can also provide relief for patients with distal disease, particularly those with rest pain. ${ }^{44}$ A review of patients undergoing isolated elective common femoral endarterectomy showed a 30-day mortality rate of $1.5 \% .{ }^{45}$ Wound infection was the most common postoperative complication divided into superficial $(6.3 \%)$ and deep (2.0\%). Other complications included septic, pulmonary, cardiac, renal, urinary tract infection, thromboembolic, and neurologic etiologies. Eight percent of patients had at least one complication postoperatively. Independent predictors of mortality included impaired preoperative functional status and dyspnea at rest. Steroid use, diabetes, and obesity predicted postoperative morbidity. Overall common femoral endarterectomy is well-tolerated 
in patients and can be the first line treatment for common femoral lesions in conjunction with bypass or alone in selected patients. ${ }^{45}$

\section{Conclusion}

Lower extremity bypass for CLI is still the predominant revascularization modality for those patients who have failed endovascular interventions and the most durable revascularization option. ${ }^{5}$ Numerous factors, both systemic and anatomical, can affect morbidity, patency, limb salvage, and mortality. Models and quality improvement projects such as with ACSNSQIP, Surgical Care Improvement Project Vascular Quality Initiative (SCIP), and VQI have attempted to identify these risk factors to better risk stratify these patients.

\section{Disclosure}

The authors report no conflicts of interest in this work.

\section{References}

1. Varu VN, Hogg ME, Kibbe MR. Critical limb ischemia. J Vasc Surg. 2010;51(1):230-241.

2. DeRubertis BG, Faries PL, McKinsey JF, et al. Shifting paradigms in the treatment of lower extremity vascular disease: a report of 1000 percutaneous interventions. Ann Surg. 2007;246(3):415-422; discussion 422-424.

3. Gallagher KA, Meltzer AJ, Ravin RA, et al. Endovascular management as first therapy for chronic total occlusion of the lower extremity arteries: comparison of balloon angioplasty, stenting, and directional atherectomy. $J$ Endovasc Ther. 2011;18(5):624-637.

4. Siracuse JJ, Giles KA, Pomposelli FB, et al. Results for primary bypass versus primary angioplasty/stent for intermittent claudication due to superficial femoral artery occlusive disease. J Vasc Surg. 2012;55(4):1001-1007.

5. Bradbury AW, Adam DJ, Bell J, et al; BASIL Trial Participants. Bypass versus Angioplasty in Severe Ischaemia of the Leg (BASIL) trial A survival prediction model to facilitate clinical decision making. J Vasc Surg. 2010;51(Suppl 5):52S-68S.

6. Meltzer AJ, Graham A, Connolly PH, et al. The Comprehensive Risk Assessment for Bypass (CRAB) facilitates efficient perioperative risk assessment for patients with critical limb ischemia. $J$ Vasc Surg. 2013;57(5):1186-1195.

7. Conte MS, Bandyk DF, Clowes AW, Moneta GL, Namini H, Seely L. Risk factors, medical therapies and perioperative events in limb salvage surgery: observations from the PREVENT III multicenter trial. $J$ Vasc Surg. 2005;42(3):456-464; discussion 464-465.

8. Menke H, Klein A, John KD, Junginger T. Predictive value of ASA classification for the assessment of the perioperative risk. Int Surg. 1993;78(3):266-270.

9. Sutton R, Bann S, Brooks M, Sarin S. The Surgical Risk Scale as an improved tool for risk-adjusted analysis in comparative surgical audit. Br J Surg. 2002;89(6):763-768.

10. Cohen ME, Bilimoria KY, Ko CY, Hall BL. Development of an American College of Surgeons National Surgery Quality Improvement Program: morbidity and mortality risk calculator for colorectal surgery. J Am Coll Surg. 2009;208(6):1009-1016.

11. Kwok AC, Lipsitz SR, Bader AM, Gawande AA. Are targeted preoperative risk prediction tools more powerful? A test of models for emergency colon surgery in the very elderly. J Am Coll Surg. 2011;213(2): 220-225.
12. Ramanan B, Gupta PK, Gupta H, Fang X, Forse RA. Development and validation of a bariatric surgery mortality risk calculator. $J \mathrm{Am}$ Coll Surg. 2012;214(6):892-900.

13. Goldman L, Caldera DL, Nussbaum SR, et al. Multifactorial index of cardiac risk in noncardiac surgical procedures. $N$ Engl $J$ Med. 1977;297(16):845-850.

14. Monahan TS, Shrikhande GV, Pomposelli FB, et al. Preoperative cardiac evaluation does not improve or predict perioperative or late survival in asymptomatic diabetic patients undergoing elective infrainguinal arterial reconstruction. J Vasc Surg. 2005;41(1):38-45; discussion 45 .

15. Bertges DJ, Goodney PP, Zhao Y, et al; Vascular Study Group of New England. The Vascular Study Group of New England Cardiac Risk Index (VSG-CRI) predicts cardiac complications more accurately than the Revised Cardiac Risk Index in vascular surgery patients. J Vasc Surg. Sep 2010;52(3):674-683, 683.e1-683.e3.

16. Crawford RS, Cambria RP, Abularrage CJ, et al. Preoperative functional status predicts perioperative outcomes after infrainguinal bypass surgery. J Vasc Surg. 2010;51(2):351-358; discussion 358-359.

17. Siracuse JJ, Gill HL, Jones DW, et al. Risk factors for protracted postoperative length of stay after lower extremity bypass for critical limb ischemia. Ann Vasc Surg. Epub February 8, 2014.

18. Pomposelli FB, Arora S, Gibbons GW, et al. Lower extremity arterial reconstruction in the very elderly: successful outcome preserves not only the limb but also residential status and ambulatory function. $J$ Vasc Surg. 1998;28(2):215-225.

19. Vogel TR, Petroski GF, Kruse RL. Functional status of elderly adults before and after interventions for critical limb ischemia. J Vasc Surg. 2014;59(2):350-358.

20. Saltzberg SS, Pomposelli FB, Belfield AK, et al. Outcome of lower-extremity revascularization in patients younger than 40 years in a predominantly diabetic population. J Vasc Surg. 2003;38(5): 1056-1059.

21. Kwolek CJ, Pomposelli FB, Tannenbaum GA, et al. Peripheral vascular bypass in juvenile-onset diabetes mellitus: are aggressive revascularization attempts justified? J Vasc Surg. 1992;15(2):394-400; discussion $400-401$.

22. Lo RC, Bensley RP, Dahlberg SE, et al. Presentation, treatment, and outcome differences between men and women undergoing revascularization or amputation for lower extremity peripheral arterial disease. J Vasc Surg. 2014;59(2):409-418. e3.

23. Siracuse JJ, Gill HL, Epelboym I, et al. Effect of race and insurance status on outcomes after vascular access placement for hemodialysis. Ann Vasc Surg. 2014;28(4):964-969.

24. Chew DK, Nguyen LL, Owens CD, et al. Comparative analysis of autogenous infrainguinal bypass grafts in African Americans and Caucasians: the association of race with graft function and limb salvage. J Vasc Surg. 2005;42(4):695-701.

25. Gibbons GW, Burgess AM, Guadagnoli E, et al. Return to wellbeing and function after infrainguinal revascularization. J Vasc Surg. 1995;21(1):35-44; discussion 44-45.

26. McArthur CS, Sheahan MG, Pomposelli FB, et al. Infrainguinal revascularization after renal transplantation. J Vasc Surg. 2003;37(6): $1181-1185$.

27. Hölzenbein TJ, Pomposelli FB, Miller A, et al. Results of a policy with arm veins used as the first alternative to an unavailable ipsilateral greater saphenous vein for infrainguinal bypass. J Vasc Surg. 1996;23(1):130-140.

28. Hamdan AD, Rayan SS, Hook SC, et al. Bypasses to tibial vessels using polytetrafluoroethylene as the solo conduit in a predominantly diabetic population. Vasc Endovascular Surg. 2002;36(1): 59-63.

29. Dake MD, Ansel GM, Jaff MR, et al; Zilver PTX Investigators. Sustained safety and effectiveness of paclitaxel-eluting stents for femoropopliteal lesions: 2-year follow-up from the Zilver PTX randomized and single-arm clinical studies. J Am Coll Cardiol. 2013;61(24): $2417-2427$. 
30. Lammer J, Zeller T, Hausegger KA, et al. Heparin-bonded covered stents versus bare-metal stents for complex femoropopliteal artery lesions: the randomized VIASTAR trial (Viabahn endoprosthesis with PROPATEN bioactive surface [VIA] versus bare nitinol stent in the treatment of long lesions in superficial femoral artery occlusive disease). J Am Coll Cardiol. 2013;62(15):1320-1327.

31. Geraghty PJ, Mewissen MW, Jaff MR, Ansel GM; VIBRANT Investigators. Three-year results of the VIBRANT trial of VIABAHN endoprosthesis versus bare nitinol stent implantation for complex superficial femoral artery occlusive disease. J Vasc Surg. 2013;58(2): 386-395. e4.

32. Werk M, Albrecht T, Meyer DR, et al. Paclitaxel-coated balloons reduce restenosis after femoro-popliteal angioplasty: evidence from the randomized PACIFIER trial. Circ Cardiovasc Interv. 2012;5(6): 831-840.

33. Misare BD, Pomposelli FB, Gibbons GW, Campbell DR, Freeman DV, LoGerfo FW. Infrapopliteal bypasses to severely calcified, unclampable outflow arteries: two-year results. J Vasc Surg. 1996;24(1):6-15; discussion 15-16.

34. Tannenbaum GA, Pomposelli FB, Marcaccio EJ, et al. Safety of vein bypass grafting to the dorsal pedal artery in diabetic patients with foot infections. J Vasc Surg. 1992;15(6):982-988; discussion 989-990.

35. Hughes K, Domenig CM, Hamdan AD, et al. Bypass to plantar and tarsal arteries: an acceptable approach to limb salvage. J Vasc Surg. 2004;40(6):1149-1157.

36. Giles KA, Hamdan AD, Pomposelli FB, Wyers MC, Siracuse JJ, Schermerhorn ML. Body mass index: surgical site infections and mortality after lower extremity bypass from the National Surgical Quality Improvement Program 2005-2007. Ann Vasc Surg. 2010;24(1):48-56.
37. Patel VI, Hamdan AD, Schermerhorn ML, et al. Lower extremity arterial revascularization in obese patients. J Vasc Surg. 2007;46(4):738-742.

38. Siracuse JJ, Nandivada P, Giles KA, et al. Prosthetic graft infections involving the femoral artery. J Vasc Surg. 2013;57(3):700-705.

39. Jansen RM, de Vries SO, Cullen KA, Donaldson MC, Hunink MG. Cost-identification analysis of revascularization procedures on patients with peripheral arterial occlusive disease. J Vasc Surg. 1998;28(4):617-623.

40. Goodney PP, Stukel TA, Lucas FL, Finlayson EV, Birkmeyer JD. Hospital volume, length of stay, and readmission rates in high-risk surgery. Ann Surg. 2003;238(2):161-167.

41. Collins TC, Daley J, Henderson WH, Khuri SF. Risk factors for prolonged length of stay after major elective surgery. Ann Surg. 1999;230(2):251-259.

42. McPhee JT, Nguyen LL, Ho KJ, Ozaki CK, Conte MS, Belkin M. Risk prediction of 30-day readmission after infrainguinal bypass for critical limb ischemia. J Vasc Surg. 2013;57(6):1481-1488.

43. Zhang JQ, Curran T, McCallum JC, et al. Risk factors for readmission after lower extremity bypass in the American College of Surgeons National Surgery Quality Improvement Program. J Vasc Surg. 2014;59(5):1331-1339.

44. Malgor RD, Ricotta JJ, Bower TC, et al. Common femoral artery endarterectomy for lower-extremity ischemia: evaluating the need for additional distal limb revascularization. Ann Vasc Surg. 2012;26(7): 946-956.

45. Siracuse JJ, Gill HL, Schneider DB, et al. Assessing the perioperative safety of common femoral endarterectomy in the endovascular era. Vasc Endovascular Surg. 2014;48(1):27-33.
Vascular Health and Risk Management

\section{Publish your work in this journal}

Vascular Health and Risk Management is an international, peerreviewed journal of therapeutics and risk management, focusing on concise rapid reporting of clinical studies on the processes involved in the maintenance of vascular health; the monitoring, prevention and treatment of vascular disease and its sequelae; and the involvement of

\section{Dovepress}

metabolic disorders, particularly diabetes. This journal is indexed on PubMed Central and MedLine. The manuscript management system is completely online and includes a very quick and fair peer-review system, which is all easy to use. Visit http://www.dovepress.com/ testimonials.php to read real quotes from published authors. 